\title{
The Southern Hemisphere Westerlies in a Warming World: \\ Propping Open the Door to the Deep Ocean
}

\author{
Joellen L. Russell ${ }^{1}$, Keith W. Dixon ${ }^{2}$, Anand Gnanadesikan ${ }^{2}$, Ronald J. Stouffer ${ }^{2}$ and J.R. \\ Toggweiler $^{2}$
}

1. Department of Geosciences, University of Arizona, Tucson, AZ 85721

jrussell@geo.arizona.edu

2. National Oceanographic and Atmospheric Administration (NOAA)

Geophysical Fluid Dynamics Laboratory, Princeton, NJ 08542

(Revised again for publication in the Journal of Climate on May 11, 2006) 


\begin{abstract}
A coupled climate model with poleward-intensified westerly winds simulates significantly higher storage of heat and anthropogenic carbon dioxide by the Southern Ocean in the future when compared to the storage in a model with initially weaker, equatorward-biased Westerlies. This difference results from the larger outcrop area of the dense waters around Antarctica and more vigorous divergence, which remains robust even as rising atmospheric greenhouse gas levels induce warming that reduces the density of surface waters in the Southern Ocean. These results imply that the impact of warming on the stratification of the global ocean may be reduced by the poleward intensification of the Westerlies, allowing the ocean to remove additional heat and anthropogenic carbon dioxide from the atmosphere.
\end{abstract}




\section{Introduction}

Increasing ocean stratification has been posited to serve as a positive feedback on global warming by reducing the storage of anthropogenic carbon dioxide and heat by the ocean (Sarmiento et al., 1998; Matear \& Hirst, 1999; Caldeira \& Duffy, 2001). We suggest that the coincident poleward intensification of westerly winds may slow the rate of stratification in the Southern Ocean, thereby slowing the decrease in the oceanic storage of heat and anthropogenic carbon dioxide due to ocean warming and stratification. Studies of ocean observations have shown that much of the oceanic heat storage in response to changes in the planet's radiative forcing occurs in the Southern Ocean (Gille, 2002; Levitus et al., 2000). The Southern Ocean is the crossroads of the global ocean's water masses, connecting the Atlantic, Pacific and Indian Oceans as well as connecting the deep ocean to the surface. The strongest time-mean oceanic winds in the world, the Southern Hemisphere Westerlies, drive the deep and vigorous Antarctic Circumpolar Current (ACC) eastward around the Antarctic continent. These winds also push the surface waters away from the Antarctic continent through Ekman transport, creating massive divergence-driven upwelling south of the current and strongly tilting the isopycnal surfaces along the path of the ACC. Water mixes preferentially along these constant density surfaces, bringing mid-depth $(2-3 \mathrm{~km})$ water into contact with the atmosphere. This process is unique to the Southern Ocean: no where else does water of this depth upwell to the surface.

Unfortunately, state of the art climate models, including those being considered as part of the Intergovernmental Panel on Climate Change (IPCC) Fourth Assessment Report (AR4) produce conflicting estimates of the storage of heat by the Southern Ocean, largely because the models differ substantially in their ability to simulate the strength and position of the Southern Hemisphere Westerly winds as well as other processes associated with the ocean component of 
the climate models (Russell et al., in press). Generally, even if the atmospheric component of a climate model simulates a reasonable meridional temperature gradient and the ocean produces a reasonable distribution of water masses, a poor simulation of the Southern Hemisphere atmospheric jet greatly distorts the oceanic simulation because most of the vertical circulations in this region are wind-driven. Models that do not simulate Southern Ocean divergence well for the present climate can be expected to distort aspects of the large-scale response to increased radiative forcing. If a model simulation has too little wind-driven divergence in the Southern Ocean then the amount of future oceanic heat storage is underestimated. Conversely, if a model suffers from too much divergence or mixing in the Southern Ocean, then the amount of future oceanic heat storage is overestimated.

Adding to the challenge of projecting changes of the Southern Ocean heat storage, observations indicate that there has been a large, and not completely understood, poleward intensification of the winds over the Southern Ocean since the 1970's. This trend in the Antarctic Oscillation (or Southern Annular Mode) has increased winds over the Southern Ocean by about 20\% over the last 20 years (Hurrell \& van Loon, 1994, Thompson \& Solomon, 2002, Gillett et al., 2003). This poleward intensification of the westerly winds is one of the most significant trends in the global climate system over the past 20 years, but few climate models have been used to evaluate the future impact of such shifts on the oceanic storage of heat and anthropogenic carbon dioxide (Fyfe et al., 1999), though most AR4 models do simulate a smaller than observed poleward shift of the Westerlies in the 20th century (Yin, 2005).

In two coupled models recently developed at GFDL, the position of the Southern Hemisphere extratropical westerly jet differs substantially under circa-1990 radiative forcing. The quality of the present-day simulation of Southern Hemisphere Westerlies and Southern 
Ocean circulation differ in the two models, with CM2.1 comparing quite favorably with observations. The Westerlies are located too far equatorward in CM2.0 - a weakness seen in many other AR4 models (Russell et al., in press). To distinguish between the competing impacts of surface warming and poleward wind intensification on ocean heat and carbon storage as greenhouse gases increase, we exploit the differences in the position and magnitude of the divergence-driven upwelling of deep waters in the Southern Ocean between GFDL's two coupled climate models (CM2.0 and CM2.1).

We hypothesize that the strength and latitude of the westerlies have a large effect on the ability of the ocean to uptake heat and carbon. Thus models in which the westerlies are inherently stronger and located further south have a likelihood of greater capacity for oceanic uptake. (We note that it is possible for models with westerlies located too far equatorward to have too much mixing in the Southern Ocean due to other model errors (Russell et al., in press).) Similarly, the tendency in global warming simulations for progressive poleward intensification of the westerlies is likely to enhance the uptake over what it would otherwise be, for the coupled climate models as a class. Further, we will present results indicating that the inherent strength and location of the model westerlies has a major effect on the impact of the global warminginduced poleward intensification on the oceanic ventilation and uptake properties.

\section{The Doubling of Atmospheric pCO (IPCC SresA1B Scenario) $^{2}$}

The IPCC has proposed several scenarios of future emissions of atmospheric greenhouse gases, most notably carbon dioxide $\left(\mathrm{CO}_{2}\right)$, methane, sulfate aerosols and chlorofluorocarbons (CFC's) (Nakicenovic et al., 2000). The scenarios used here combine information about projected emissions due to fossil fuel burning and land use changes. The future time histories of 
the concentrations of the radiatively active constituents are derived from the SRES emission scenarios and have been used to force coupled climate model simulations to evaluate and estimate their impacts on surface temperatures, the hydrological cycle, the ocean circulation, terrestrial productivity and other climatically and socially important issues. The scenario considered in this study, SresA1B, assumes that the amount of $\mathrm{CO}_{2}$ in the atmosphere will reach double present-day concentrations by the year 2100 and stabilize at 717 parts per million (ppm).

In support of the IPCC's Fourth Assessment effort, two coupled models at GFDL with nearly identical ocean, land and ice components and different atmospheric model components are used to simulate the anthropogenically-influenced future. The details of the coupled climate model, including the specific differences relating to the atmospheric dynamical cores, are presented in Delworth et al. (2006). Detailed descriptions of the formulation of the ocean component and the physical parameterizations are presented in Griffies et al. (2005) and an evaluation of the overall oceanic solution is given in Gnanadesikan et al. (2006). The fact that these climate simulations express different surface westerly wind regimes over the Southern Ocean will be exploited in this study. One of the GFDL models, CM2.1 hereafter, when forced with the constant IPCC present-day control (PDCNTRL) parameters, has very strong surface westerly winds, realistically situated over the Antarctic Circumpolar Current (ACC). The other GFDL model, CM2.0 hereafter, has weaker surface westerly winds that are positioned equatorward of the ACC.

\section{Response to Poleward Shifted and Strengthened Westerly Winds}

It is our contention that the initial position and strength of the westerly winds over the Southern Ocean are the primary reasons for the differences between the two experiments' 
simulated oceanic storage of heat and carbon. The wind stress is initially higher in CM2.1 than in CM2.0 (by $\sim 10 \%$ ) and is located about $4^{\circ}$ further south (Fig. 1). The effects of the increasing radiative forcing in the SresA1B scenario are consistent across both of our experiments: the Southern Hemisphere Westerlies increase in strength by $9 \%$ in CM2.1 and 8\% in CM2.0 (Fig. 1A) and move poleward by about $1^{\circ}$ of latitude (Fig 1B). The shift of the Westerlies towards the pole in the SH is seen in many models (Fyfe et al. 1999, Kushner et al. 2001, Cai et al. 2005).

As the wind stress increases, both the strength of the Antarctic Circumpolar Current and the mean thermal and salinity gradients in the upper water column across the ACC are affected, as in other studies (Meredith et al., 2004, Fyfe and Saenko, 2005). The ACC is stronger in CM2.1 than in CM2.0 at all times and is still increasing in both experiments at year 2300 (Fig. 1C). Likewise, the thermal gradient across the ACC (Fig. 1D, the difference between $45^{\circ} \mathrm{S}$ and $65^{\circ} \mathrm{S}$ ) is always larger in $\mathrm{CM} 2.1$. In both experiments, the thermal gradient is still increasing at year 2300 . The mean salinity gradient (Fig $1 \mathrm{D}$, the difference between $65^{\circ} \mathrm{S}$ and $45^{\circ} \mathrm{S}$ ) is larger in CM2.0, but the relative change is larger in CM2.1, with poleward-shifted Westerlies, over the course of the integration.

Ventilation of the ocean (exposure to the atmosphere) depends on two competing forces: the strength of the wind-driven divergence and the strength of the opposing stratification from warming and freshening. The surface outcrop area of the Antarctic Intermediate Water isopycnal $\left(\sigma_{\theta}=27.1\right.$, the yellow region, Fig. 2) is the location where water denser than Antarctic Intermediate Water is exposed to the atmosphere and indicates where the wind-driving is still strong enough to overcome the stratification. During the transient integration, the increasing surface warming and the deepening of the isopcynal layers is offset somewhat by the increased wind stress. The surface outcrop is significantly larger at the start of CM2.1 (26.0 million sq. 
km., Figure 2A) than it is at the start of CM2.0 (14.4 million sq. km., Figure 2D), and compares quite well to the observations (31.0 million sq. km, Conkwright et al., 2002). Thus, the larger the outcrop, the more dense water is exposed to the atmosphere and the more heat and carbon that can be taken up as the climate changes. As is clear in Figure 2, the depth of the AAIW isopycnal deepens as the surface ocean warms $(\mathrm{C}, \mathrm{F})$ and the outcrop area decreases in both experiments, but remains significantly larger in CM2.1 after 300 years (B) than in CM2.0 after 300 years (E).

In fact, as is seen in Figure 3A, the area of the outcrop at the end of CM2.1 experiment is still larger than it was at the beginning of the CM2.0 experiment. The area of dense water exposure to the atmosphere remains large in CM2.1 despite the warming. This is also apparent in an analysis of an "ideal" ocean age tracer implemented in both model simulations. Ideal age is a tracer set to zero instantaneously in the surface layer of the model and then ages at a rate of $1 \mathrm{yr} / \mathrm{yr}$ away from the surface. The ideal age measures the time since water has last been at the surface and serves as a measure of the locations and rates at which the ocean is ventilated. Figure 3B shows the volume of water, south of $30^{\circ} \mathrm{S}$, with an idealized age of less than 50 years. The ventilation of the Southern Ocean, as revealed by the idealized age tracer, increases over the course of the CM2.1 experiment indicating that the effects of wind-driven divergence are stronger than the stratification increases due to warming. The CM2.0 experiment, with an initial equatorward-bias in the westerlies' position, shows little increased ventilation despite the subsequent poleward shift (Fig 1B) and increase in magnitude (Fig 1A) of the maximum wind stress during the course of the simulation. The increase in the volume of younger waters in CM2.1 is largely due to the wind-driven upwelling of deeper, older waters to the surface to replace surface waters pushed away from Antarctica through Ekman transport 


\section{The Storage of Heat and Carbon}

When forced with an increasing atmospheric burden of carbon dioxide and other greenhouse gases, both models predict an increase in the mean oceanic temperature and thus its heat content. Though each region warms in both runs, all regions warm by a larger amount in the CM2.1 model with poleward intensified winds relative to the change in CM2.0 (Fig. 4A). The heat storage is defined as the temperature difference from year 2000 integrated over the given volume, converted into Joules (after multiplying by the density and the specific heat capacity). The relative increase in the Southern Ocean heat content (blue solid line minus blue dashed line) makes up the largest part of the global difference between the runs, even though, due to its larger volume, the heat content of the Indian and Pacific Oceans increases the most. Although a small trend in the heat content remains in both Control runs (not shown), it is negligible in comparison to the clear increases seen in Fig. 4A

The full suite of carbon cycle tracers was not included in the two GFDL model simulations. We infer the solubility-related anthropogenic carbon storage (Fig. 4B) by calculating the saturated carbon content based on the ideal age, temperature and salinity from the models, and the $\mathrm{pH}$ calculated from the observed dissolved inorganic carbon (DIC) and alkalinity distributions, and the prescribed atmospheric $\mathrm{CO}_{2}$ at the time the parcel was ventilated. We should note that mixing of idealized age tracers in ocean models will generally bias the solution toward the older water, which in our case will imply a lower atmospheric $\mathrm{CO}_{2}$. Sabine et al., (2004) used water age estimates (based on chlorofluorocarbons) to determine when a water parcel was last in contact with the atmosphere to calculate past uptake of anthropogenic carbon by the ocean. To estimate the future storage of anthropogenic carbon dioxide, we simplify the technique by assuming 100 percent saturation with respect to the atmospheric $\mathrm{pCO}_{2}$ over a 5- 
year period. We also assume an unchanging biological pump and $\mathrm{pH}$ distribution (ignoring the effect of buffering). Based on the idealized age, we know the year that a water parcel was last at the surface, and therefore the atmospheric pCO2 at that time. The inferred anthropogenic $\mathrm{CO} 2$ concentration is estimated by:

$$
\mathrm{C}_{\text {anth }}=\mathrm{C}_{\mathrm{sat}}-\mathrm{C}_{\mathrm{GLODAP}}
$$

where $\mathrm{C}_{\text {sat }}$ is the saturation value of DIC calculated from the modeled temperature and salinity, the modern $\mathrm{pH}$ at that location, and atmospheric $\mathrm{pCO}_{2}$ (Dickson \& Goyet, 1994), and where $\mathrm{C}_{\text {GLODAP }}$ is the modern distribution of DIC from GLODAP (Key et al., 2004). If the saturated concentration of DIC is less than the modern observed concentration of DIC at the same location, then the uptake of anthropogenic carbon is assumed to be zero.

When waters mix, the calculation yields reasonable values. For example, consider a mixture of water, half of age 500 years and half of age 10 years. The water parcel that was 500 years old might be supersaturated with respect to carbon, equivalent to an atmospheric $\mathrm{pCO}_{2}$ of about $450 \mathrm{ppm}$ due to the accumulation of respired organic material (we get this number from the DIC distribution from GLODAP). This parcel, if ventilated, would outgas regardless of whether the forcing scenario used in the model was the present day, with an atmospheric $\mathrm{pCO}_{2}$ of $380 \mathrm{ppm}$, or the pre-industrial, with an atmospheric $\mathrm{pCO}_{2}$ of $285 \mathrm{ppm}$. If the parcel was mixed with an equal amount of water that was ventilated 10 years ago at a $\mathrm{pCO}_{2}$ of 360 , it would still degas, since it would still be supersaturated with respect to carbon (with a $\mathrm{pCO}_{2}$ of approximately $405 \mathrm{ppm}$ ). Under these conditions, our calculation would not diagnose any uptake of anthropogenic carbon dioxide.

From these calculations, we see that the inferred increase in solubility-related carbon content closely mirrors the increase in heat content. The rise is steepest over the first 100 years as 
the atmospheric $\mathrm{CO}_{2}$ content is ramping up, but continues to increase even after the atmospheric $\mathrm{CO}_{2}$ stabilizes. During the first fifty years, the rate of increase in ocean carbon storage is determined by the equilibration of the surface ocean with the $\mathrm{CO}_{2}$-enriched atmosphere, resulting in similar rates of increase for both CM2.0 and CM2.1 (Fig. 4B). After the atmospheric concentration of carbon dioxide plateaus in 2100, the deep-water equilibration becomes a progressively larger fraction of the increase in ocean storage of anthropogenic carbon dioxide. Despite its significantly smaller volume, the Southern Ocean has stored more solubility-related anthropogenic carbon than the Indian and Pacific Oceans by year 2300 in the CM2.1 experiment. The differences in implied anthropogenic carbon storage between the two experiments are smallest in the Indian and Pacific, the least well ventilated of the ocean basins.

The column inventories of heat and carbon (Figure 5A and 5B) illustrate the global distribution of the response of CM2.1 to the shifted winds over the period 2000-2300, which allows for a greater oceanic storage of both heat and carbon in the SresA1B scenario in every region relative to CM2.0. As was seen in Fig. 4A, the increase in heat content (Figure 5A) is largest in the Southern Ocean, specifically in the Atlantic sector. The difference in the amount of warming between models is clearly related to the amount of ventilation: the Atlantic is both ventilated and warms more than the Indian, which is better ventilated and warms more than the Pacific. In the South Pacific, the storage of heat is greater in CM2.0 (the model simulation with equatorward-biased winds) than in CM2.1 because the Tasman Front, the southward moving warm current located north of New Zealand, is unrealistically large in CM2.0 relative to CM2.1 and observations.

Consistent with the change in heat content, the implied increase in "carbon" storage is greater in CM2.1 than CM2.0 nearly everywhere in the Southern Hemisphere and less so in the 
North (Figure 5B). Throughout the Atlantic and the Southern Ocean, especially in the Weddell Sea and those regions ventilated by Antarctic Intermediate Water (AAIW) (Talley, 2003), CM2.1 has a greater increase in carbon content than CM2.0. In those regions downstream from the Ross Sea, the Sea of Okhotsk, the Labrador Sea, the Red Sea and the shallow regions around Indonesia and Australia, CM2.0 takes up slightly more carbon, because at the start of the experiments (year 2001-2020), these regions were already being fully ventilated in CM2.1 and less so in CM2.0. In these areas, the relative change between the start and the end of each run (years 2281-2300), therefore, is greater in CM2.0 than in CM2.1.

There are several caveats to our analysis that need to be pointed out. First, more work needs to be done to understand why the atmospheric simulations in CM2.0 and CM2.1 are different. Details of the differing solutions may be relevant to the response to a warming climate. Second, at least some of the last 30-year observed poleward trend in the Westerlies may be a short-term fluctuation, rather than a long-term trend, and may reverse in the future. The studies of Fyfe et al. (1999), Shindell et al. (1999) and others have both linked the trends in the Southern Annual Mode to tropospheric warming, but more research is necessary. The third, and potentially most suspect part of our analysis, are our assumptions about ocean carbon. The assumption of an unchanging $\mathrm{pH}$ distribution is at best a shortcut. We know that titrating the ocean with anthropogenic carbon dioxide will eventually lead to a lower $\mathrm{pH}$ and therefore lower carbon dioxide solubility, particularly in the equatorial thermocline, but our method does not include this effect (Caldeira and Wickett, 2003). In addition, our analysis is based on solubility calculations only and assumes that the biological cycling of carbon will remain constant, rather than estimating the impacts explicitly or mediating between the conflicting predictions in the scientific community of whether marine ecosystems will thrive in a $\mathrm{CO}_{2}$-enhanced world (Feely 
et al., 2004; Gregg et al., 2003). We note, however, that an age scale derived from an exponentially increasing atmospheric gas will always weight the mixing of water parcel ages toward the older water mass (which has none of the gas in it). Based on this feature, it is likely that our technique will underestimate the ventilation year and therefore will underestimate the derived saturated carbon content and the potential anthropogenic uptake. The obvious next step in this analysis is to explicitly calculate the biological response to the change in ocean circulation and carbon storage.

\section{Propping Open the Door to the Deep Ocean}

Imagine that your kitchen is the world ocean and the oven is the atmosphere. When you turn the oven on with its door closed, the oven heats up and so, more slowly, does the entire kitchen. Now imagine that you leave the oven door open as the oven is heating: the kitchen warms faster, but the oven warms more slowly when compared to the case where the oven door is shut. The wind-driven ventilation of the Southern Ocean is like the oven door. Strong surface westerly winds over the Southern Ocean push surface waters away from Antarctica, keeping the door between the atmosphere and the deep ocean open. As the winds strengthen, the door, located to the south of the Subantarctic Front (south of the maximum wind stress curl change), is opened wider. If, however, the heating and/or freshening of the Southern Ocean surface increase the stratification faster than the poleward intensification of the winds can decrease the stratification, the door to the cold, deep ocean will close, allowing the warming in the atmosphere to accelerate and the oceanic heat storage to slow.

The large, observed poleward shift of the Southern Hemisphere Westerlies over the past few decades suggests that the oven door in the real world might be propped open by the winds 
against the increased surface ocean warming and stratification that threaten to force the door closed. In GFDL's CM2.1 model the door to the deep ocean is open only slightly less widely than in observations and responds to climate warming and wind intensification by ventilating more water. However, in most of the AR4 simulations of the present climate, including CM2.0, the oven door is already closed more than in the observations (Russell et al., in press). In these models, the increased stability from the warming and freshening of the Southern Ocean as the climate warms closes the oven door further, allowing more of the heat and carbon to remain in the atmosphere. In a few AR4 models, the oven door is effectively stuck wide open (Russell et al., in press) and we believe that those models would likely simulate an unrealistically large storage of heat and carbon by the Southern Ocean.

Assuming that the magnitude of the wind stress is relatively close to the observed value (say within $20 \%$ or so), then it seems to us that the location of the westerlies is the single most important factor in getting the control Southern Ocean simulation correct. Obviously, many other model errors can impact the Southern Ocean and a careful analysis must be performed before making an judgment on the quality of a given model's response to increasing greenhouse gases is reliable.

While the storage of heat and carbon by the ocean help delay the climate changes in the atmosphere, the impacts on the ocean are important to consider. In addition to the sea level rise from water added to the oceans as the polar ice caps melt, seawater expands as it warms, adding to the potential sea level rise. The larger the oceanic heat sequestration is, the smaller the increase in surface air temperature, but the larger the implied steric sea level rise. As a corollary, the larger the solubility-derived ocean carbon storage is, the smaller the increase in radiative forcing and associated climate warming. However, the biological response to the projected 
decrease in the $\mathrm{pH}$ of the ocean from titration with anthropogenic carbon dioxide and the increase in global ocean stratification add significant uncertainty to the implications of these results.

Here we use the CM2.1 simulation as an example where the divergence-driven door to the deep ocean is open approximately as wide as observed today (with the caveats noted). In the projections of future climate presented here, realistically located westerly winds over the Southern Ocean and their poleward intensification as the climate warms lead to more divergence, greater ventilation, and the potential for enhanced storage of heat and anthropogenic carbon dioxide by the ocean. In the CM2.1 case, the poleward intensified Westerlies oppose the increased stratification associated with global warming, allowing the door to the deep ocean to remain open, so that by year 2300 the ocean in CM2.1 absorbs $24 \%$ more heat and $25 \%$ more carbon when compared with the CM2.0 simulation. If continuing intensification of the Westerlies outpaces the ocean warming and stratification associated with increases in atmospheric carbon dioxide, the deep ocean has the potential to slow the warming of the atmosphere through the increased storage of heat and carbon. 


\section{References}

Cai, W.J., G. Shi, T. Cowan, D. Bi, and J. Ribbe, 2005: The response of the Southern Annular Mode, the East Australian Current, and the southern mid-latitude ocean circulation to global warming. Geophys. Res. Lett., 32, L23706, doi:10.1029/2005GL024701, 2005.

Cai, W.J., P.H. Whetton, and D.J. Karoly, 2003: The response of the Antarctic oscillation to increasing and stabilized atmospheric $\mathrm{CO}_{2}$. J. Climate, 16, 1525-1538.

Caldeira, K, and P.B. Duffy, 2000: The role of the Southern Ocean in uptake and storage of anthropogenic carbon dioxide, Science, 287, 620-622.

Caldeira, K., and M.E. Wickett, 2003: Anthropogenic carbon and ocean pH, Nature, 425, 365.

Conkright, M.E., R. A. Locarnini, H.E. Garcia, T.D. O’Brien, T.P. Boyer, C. Stephens, J.I. Antonov, 2002: World Ocean Atlas 2001: Objective Analyses, Data Statistics, and Figures, CD-ROM Documentation. National Oceanographic Data Center, Silver Spring, MD, 17 pp.

Delworth, T., and 39 others: GFDL's CM2 global coupled climate models- Part 1: Formulation and simulation characteristics, J. Climate. (In press).

Department of Energy, 1994: Handbook of Methods for the Analysis of the Various Parameters of the Carbon Dioxide System in Sea Water, Version 2, A.G. Dickson and C. Goyet, eds. ORNL/CDIAC-74, http://132.239.122.17/co2qc/handbook.html.

Feely, R.A., C.L. Sabine, K. Lee, W. Berelson, J. Kleypas, V.J. Fabry, and F.J. Millero, 2004: Impact of Anthropogenic $\mathrm{CO}_{2}$ on the $\mathrm{CaCO}_{3}$ System in the Oceans, Science, 305, 362366.

Fyfe, J.C., G.J. Boer and G.M. Flato, 1999: The Arctic and Antarctic Oscillations and their projected changes under global warming. Geophys. Res. Lett., 26, 1601-1604. 
Fyfe, J.C. and O.A. Saenko, 2005: Human-induced change in the Antarctic Circumpolar Current. J. Climate, 18, 3068-3073.

Gille, S.T., 2002: Warming of the Southern Ocean since the 1950's. Science, 295, 1275-1277.

Gillett, N.P., F.W. Zwiers, A.J. Weaver, and P.A. Stott, 2003: Detection of human influence on sea-level pressure. Nature, 422, 292-294.

Gnanadesikan, A. and 27 others, in press: GFDL's CM2 global coupled climate models- Part 2: The baseline ocean simulation, J. Climate.

Gregg, W.W., M.E. Conkwright, P. Ginoux, J.E. O’Reilly, and N.W. Casey, 2003: Ocean primary production and climate: Global decadal changes, Geophys. Res. Lett., 30, 1809, doi:10/1029/2003GL016889.

Griffies, S.M., et al., 2005: Formulation of an ocean model for a coupled climate simulation, Ocean Modeling, 1, 45-79.

Hurrell, J. W., and H. van Loon, 1994: A modulation of the atmospheric annual cycle in the Southern Hemisphere, Tellus, 46A, 325-338.

Key, R. M., A. Kozyr, C. L. Sabine, K. Lee, R. Wanninkhof, J. L. Bullister, R. A. Feely, F. J. Millero, C. Mordy, and T.-H. Peng, 2004: A global ocean carbon climatology: Results from Global Data Analysis Project (GLODAP), Global Biogeochem. Cycles, 18, GB4031, doi:10.1029/2004GB002247.

Levitus, S., J.L. Antonov, T.P. Boyer and C. Stephens, 2000: Warming of the world ocean. Science, 287, 2225-2229.

Matear, R.J., and A.C. Hirst, 1999: Climate change feedback on the future oceanic $\mathrm{CO}_{2}$ uptake, Tellus, 51B, 722-733. 
Meredith, M.P., P.L. Woodworth, C.W. Hughes, and V. Stepanov, 2004: Changes in the ocean transport through Drake Passage during the 1980s and 1990s, forced by changes in the Southern Annular Mode, Geophys. Res. Lett., 31, L21305, doi:10,1029/2004GL021169.

Nakicenovic, N. et al., 2000: IPCC Special Report on Emission Scenarios, Cambridge Univ. Press, Cambridge, 595 pp.

Russell, J.L., R.J. Stouffer, and K.W. Dixon: Intercomparison of the Southern Ocean Circulations in IPCC Coupled Model Control Simulations, J. Climate, (accepted).

Sabine, C.L., R.A. Feely, N. Gruber, R.M. Key, K. Lee, J.L. Bullister, R. Wanninkhof, C.S. Wong, D.W.R. Wallace, B. Tillbrook, F.J. Millero, T.-H. Peng, A. Kozyr, T. Ono, and A.F. Rios, 2004: The Oceanic Sink for Anthropogenic $\mathrm{CO}_{2}$, Science, 305, 367-371.

Sarmiento, J.L., T.M.C. Hughes, R.J. Stouffer, and S. Manabe, 1998: Simulated response of the ocean carbon cycle to anthropogenic climate warming. Nature, 393, 245-249.

Shindell, D. T., R. L. Miller, G. A. Schmidt, and L. Pandolfo, 1999: Simulation of recent northern winter climate trends by greenhouse-gas forcing, Nature, 399, 452-455.

Talley, L. D., 2003: Shallow, intermediate and deep overturning components of the global heat budget. J. Phys. Oceanogr., 33, 530-560.

Thompson, D.W.J. and S. Solomon, 2002: Interpretation of recent Southern Hemisphere climate change. Science, 296, 895-899.

Yin, J.H., 2005: A Consistent Poleward Shift of the Storm tracks in Simulations of $21^{\text {st }}$ Century Climate, Geophys. Res. Lett., 32, L18701, doi:10.1029/2005GL023684. 


\section{Figure Captions}

1) Time series of (A) the maximum, zonally-averaged wind stress between $70^{\circ} \mathrm{S}$ and $30^{\circ} \mathrm{S}$, (B) the latitude of the maximum zonally-averaged wind stress, $(\mathrm{C})$ the strength of the ACC transport at Drake Passage, and (D) the mean temperature (solid) and salinity (solid with circles) differences (averaged globally from the surface to $2500 \mathrm{~m}$ depth) between $65^{\circ} \mathrm{S}$ and $45^{\circ} \mathrm{S}$. In all panels, the black line is the result from CM2.1 experiment and the red line is the result from CM2.0 experiment. The blue line in (A) is the time history of atmospheric $\mathrm{CO}_{2}$ used to force both model runs. An 11-year centered running mean filter has been applied to each of the curves.

2) Depth of the $\sigma_{\theta}=27.1$ isopycnal surface (in meters), the conventional proxy for Antarctic Intermediate Water (Talley, 2003) at A) the start of the CM2.1 Experiment; B) the end of the CM2.1 experiment; D) the start of the CM2.0 experiment; and E) at the end of the CM2.0 experiment. Those areas where the isopycnal outcrops or is less than $100 \mathrm{~m}$ deep are shaded in yellow. Those areas in which the water column is everywhere less dense than 27.1 are shaded in dark gray. Also shown are the change in depth of the AAIW isopycnal (in meters) for C) the CM2.1 experiment, and F) the CM2.0 experiment. Dark gray regions in C) and F) are locations where the water column is lighter than 27.1 at all depths at all times. 
3) A) The integrated outcrop area (the yellow regions in Fig. 2) over the course of the SresA1B scenario for CM2.1 (black) and CM2.0 (red). B) The integrated volume of water younger than 50 years old (south of $30^{\circ} \mathrm{S}$ ) over the same period of time.

4) The cumulative uptake of (A) heat and (B) carbon for the CM2.1 (solid) and CM2.0 (dashed) SresA1B scenarios over the global ocean $\left(0^{\circ} \mathrm{E}-360^{\circ} \mathrm{E}, 90^{\circ} \mathrm{S}-90^{\circ} \mathrm{N}\right.$, black), the Southern Ocean $\left(0^{\circ} \mathrm{E}-360^{\circ} \mathrm{E}, 90^{\circ} \mathrm{S}-30^{\circ} \mathrm{S}\right.$, blue $)$, the Indo-Pacific Ocean $\left(20^{\circ} \mathrm{E}-80^{\circ} \mathrm{W}, 30^{\circ} \mathrm{S}-90^{\circ} \mathrm{N}\right.$, green), and the Atlantic Ocean $\left(80^{\circ} \mathrm{W}-20^{\circ} \mathrm{E}, 30^{\circ} \mathrm{S}-90^{\circ} \mathrm{N}\right.$, red). Our methods for calculating both the heat and anthropogenic carbon storage are described in the text.

5) The difference in the (A) vertically integrated heat storage; and (B) the implied "carbon" storage (column inventory) between the CM2.1 and CM2.0 experiments over the period from 2000 to 2300 . We calculated the storage of both heat and carbon over the last 20 years of each run (2281-2300) and subtracted the storage from the first 20 years of each run (20012020). We then subtracted the results of CM2.0 from CM2.1. 
Figure 1:

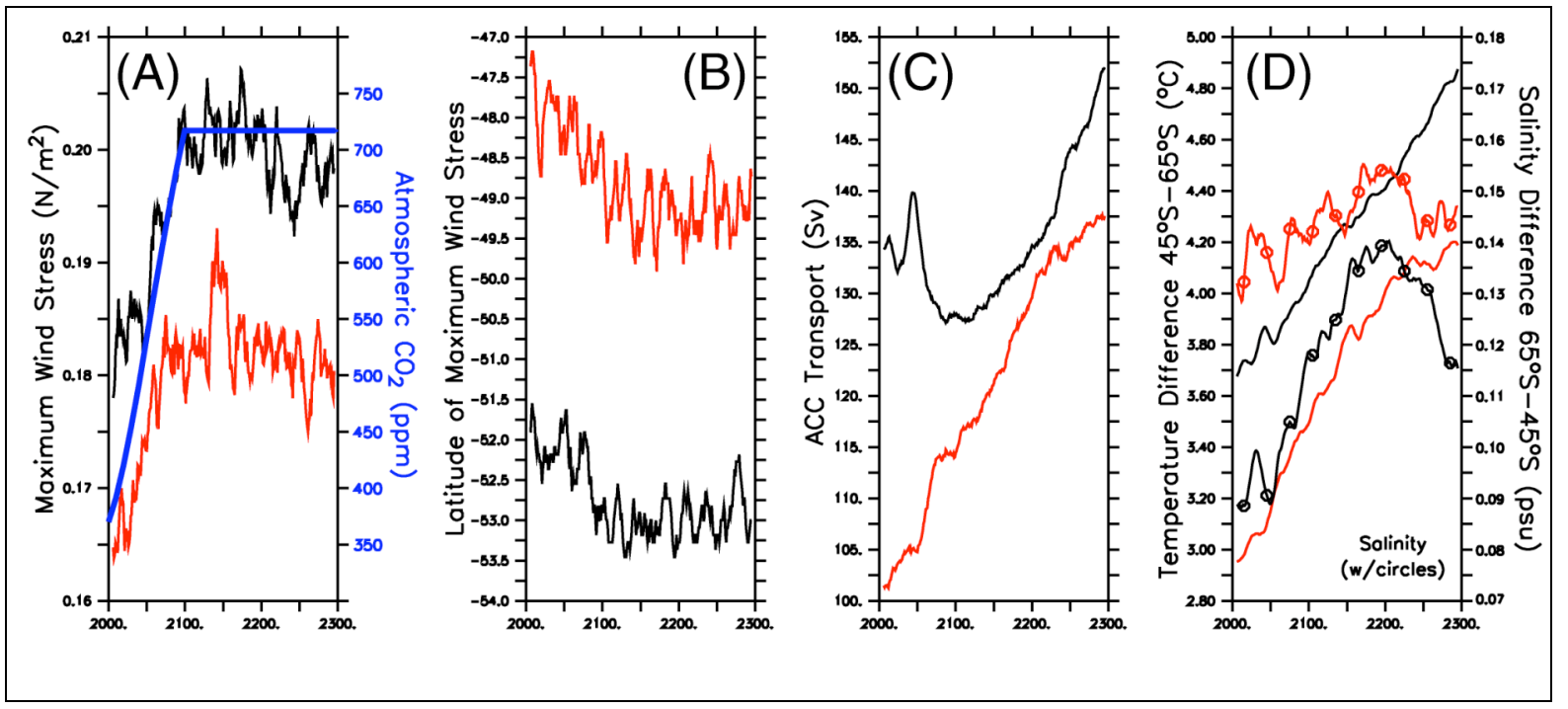

Figure 1: Time series of (A) the maximum, zonally-averaged wind stress between $70^{\circ} \mathrm{S}$ and $30^{\circ} \mathrm{S}$, (B) the latitude of the maximum zonally-averaged wind stress, (C) the strength of the ACC transport at Drake Passage, and (D) the mean temperature (solid) and salinity (solid with circles) differences (averaged globally from the surface to $2500 \mathrm{~m}$ depth) between $65^{\circ} \mathrm{S}$ and $45^{\circ} \mathrm{S}$. In all panels, the black line is the result from $\mathrm{CM} 2.1$ experiment and the red line is the result from CM2.0 experiment. The blue line in $(\mathrm{A})$ is the time history of atmospheric $\mathrm{CO}_{2}$ used to force both model runs. An 11-year centered running mean filter has been applied to each of the curves. 
Figure 2:

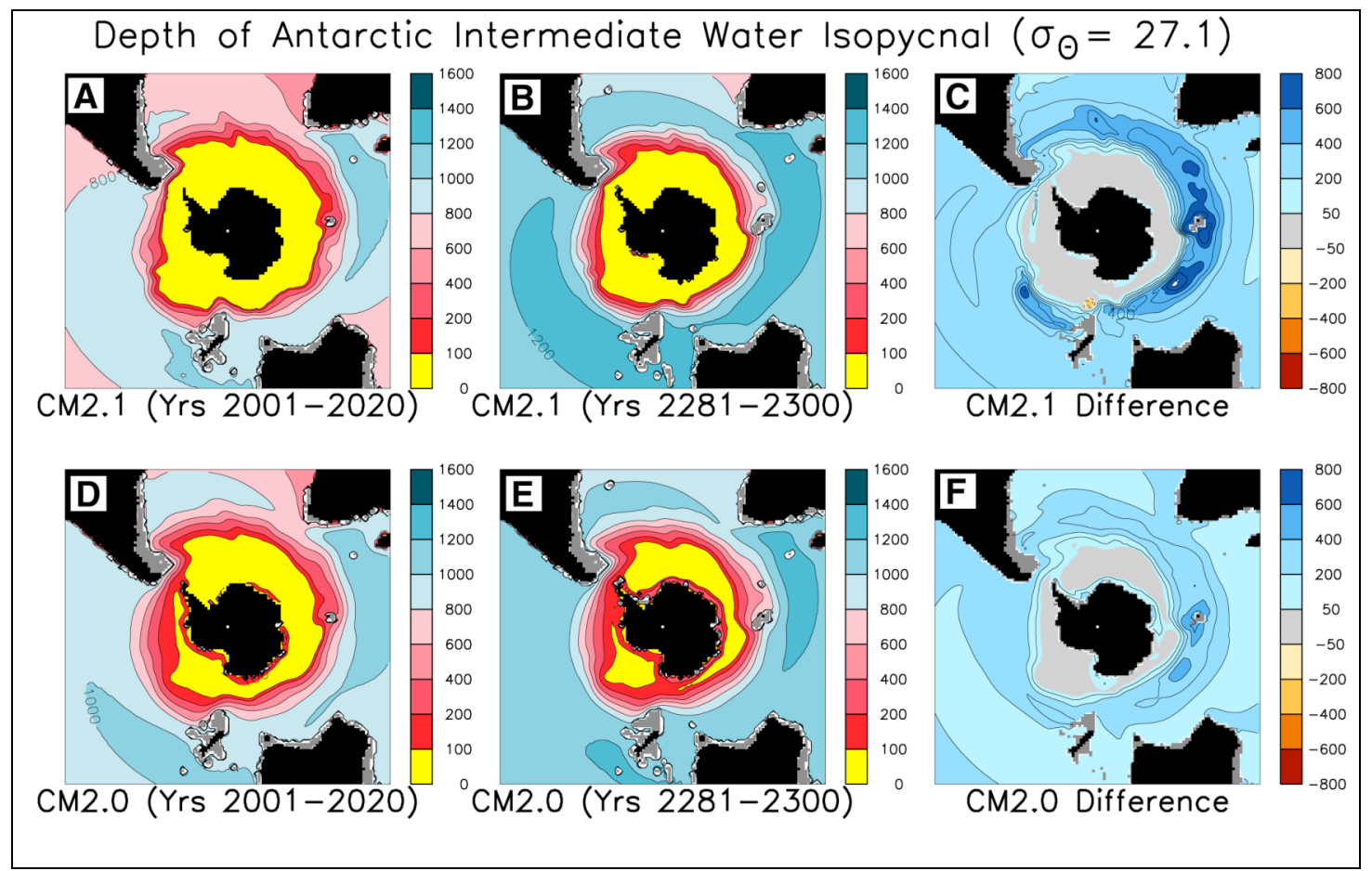

Figure 2: Depth of the $\sigma_{\theta}=27.1$ isopycnal surface (in meters), the conventional proxy for Antarctic Intermediate Water (Talley, 2003) at A) the start of the CM2.1 Experiment; B) the end of the CM2.1 experiment; D) the start of the CM2.0 experiment; and E) at the end of the CM2.0 experiment. Those areas where the isopycnal outcrops or is less than $100 \mathrm{~m}$ deep are shaded in yellow. Those areas in which the water column is everywhere less dense than 27.1 are shaded in dark gray. Also shown are the change in depth of the AAIW isopycnal (in meters) for $\mathrm{C}$ ) the CM2.1 experiment, and F) the CM2.0 experiment. Dark gray regions in C) and F) are locations where the water column is lighter than 27.1 at all depths at all times. 
Figure 3:

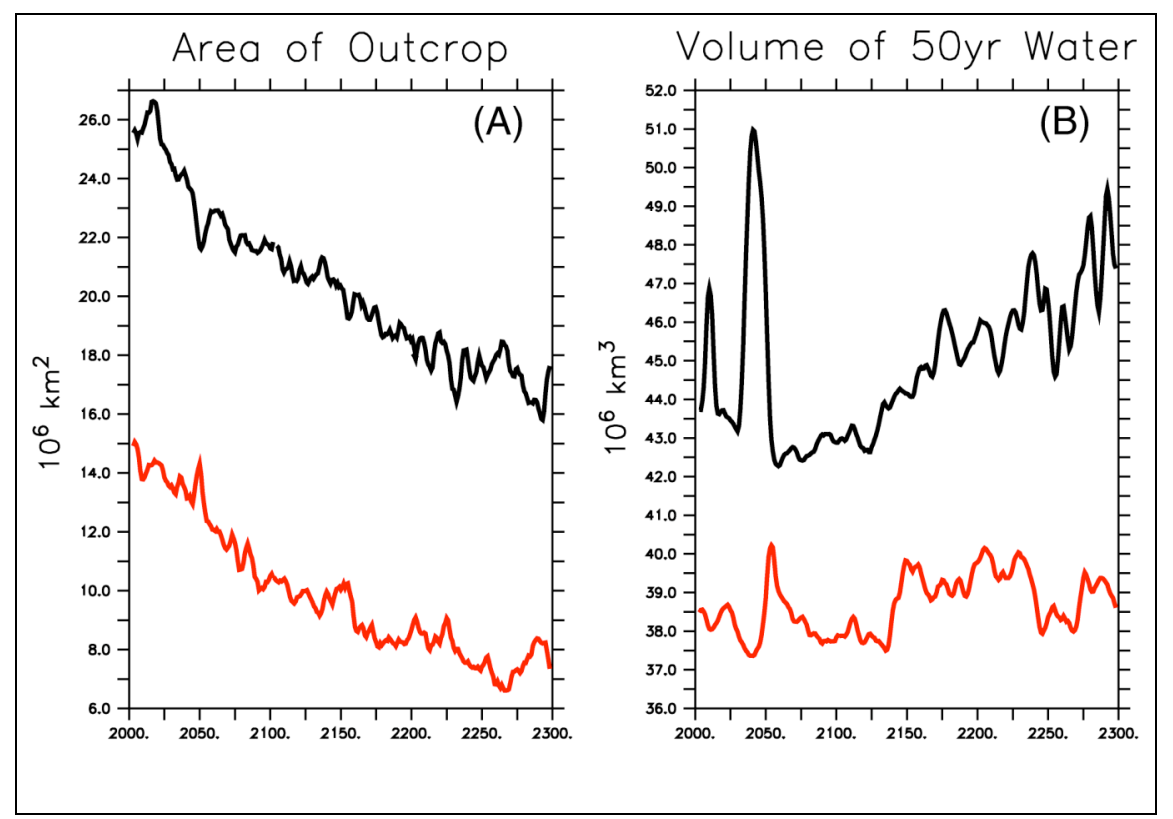

Figure 3: A) The integrated outcrop area (the yellow regions in Fig. 2) over the course of the SresA1B scenario for CM2.1 (black) and CM2.0 (red). B) The integrated volume of water younger than 50 years old (south of $30^{\circ} \mathrm{S}$ ) over the same period of time. 
Figure 4:

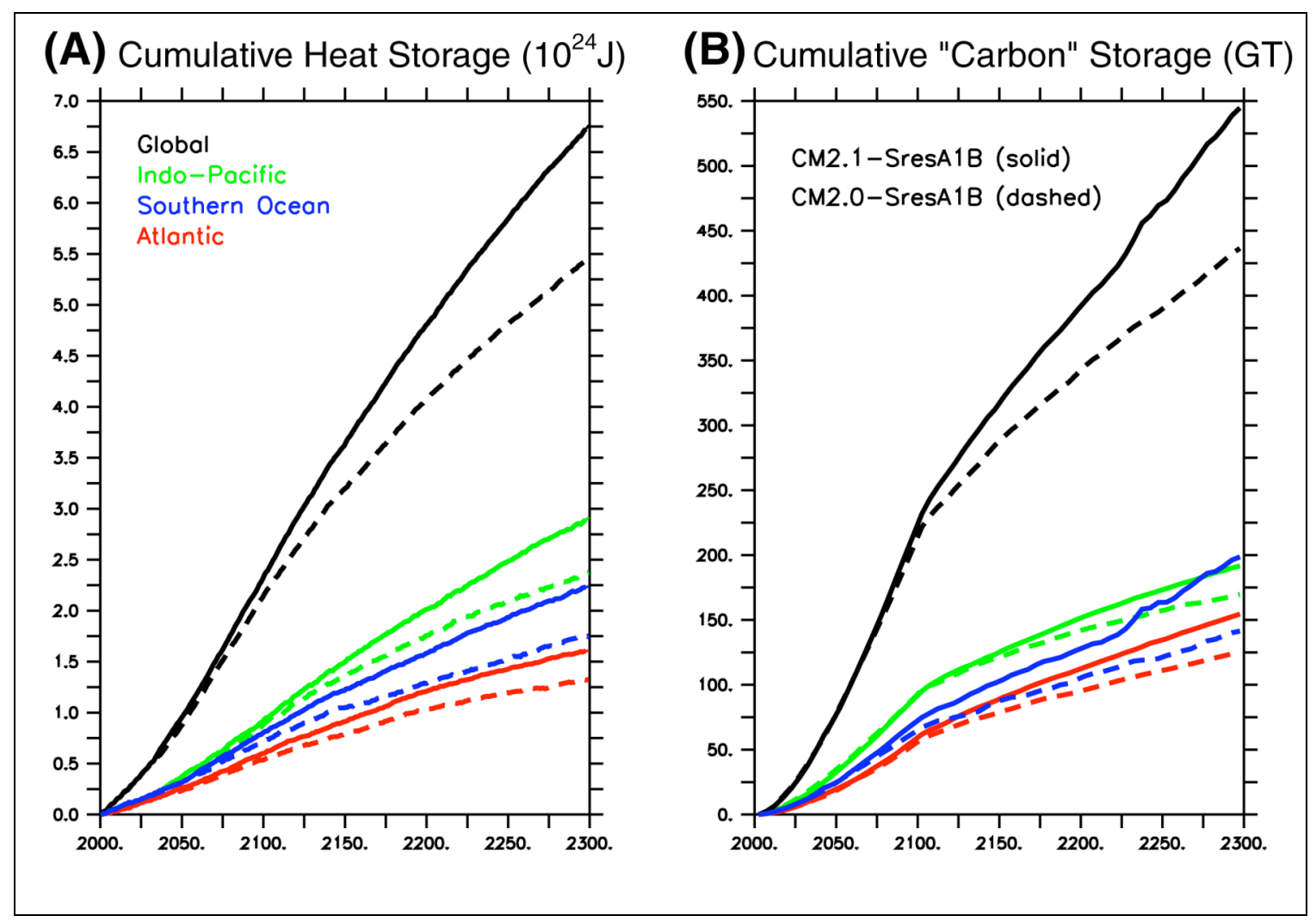

Figure 4: The cumulative uptake of (A) heat and (B) carbon for the CM2.1 (solid) and CM2.0 (dashed) SresA1B scenarios over the global ocean $\left(0^{\circ} \mathrm{E}-360^{\circ} \mathrm{E}, 90^{\circ} \mathrm{S}-90^{\circ} \mathrm{N}\right.$, black$)$, the Southern Ocean $\left(0^{\circ} \mathrm{E}-360^{\circ} \mathrm{E}, 90^{\circ} \mathrm{S}-30^{\circ} \mathrm{S}\right.$, blue $)$, the Indo-Pacific Ocean $\left(20^{\circ} \mathrm{E}-80^{\circ} \mathrm{W}\right.$, $30^{\circ} \mathrm{S}-90^{\circ} \mathrm{N}$, green), and the Atlantic Ocean $\left(80^{\circ} \mathrm{W}-20^{\circ} \mathrm{E}, 30^{\circ} \mathrm{S}-90^{\circ} \mathrm{N}\right.$, red). Our methods for calculating both the heat and anthropogenic carbon storage are described in the text. 
Figure 5:

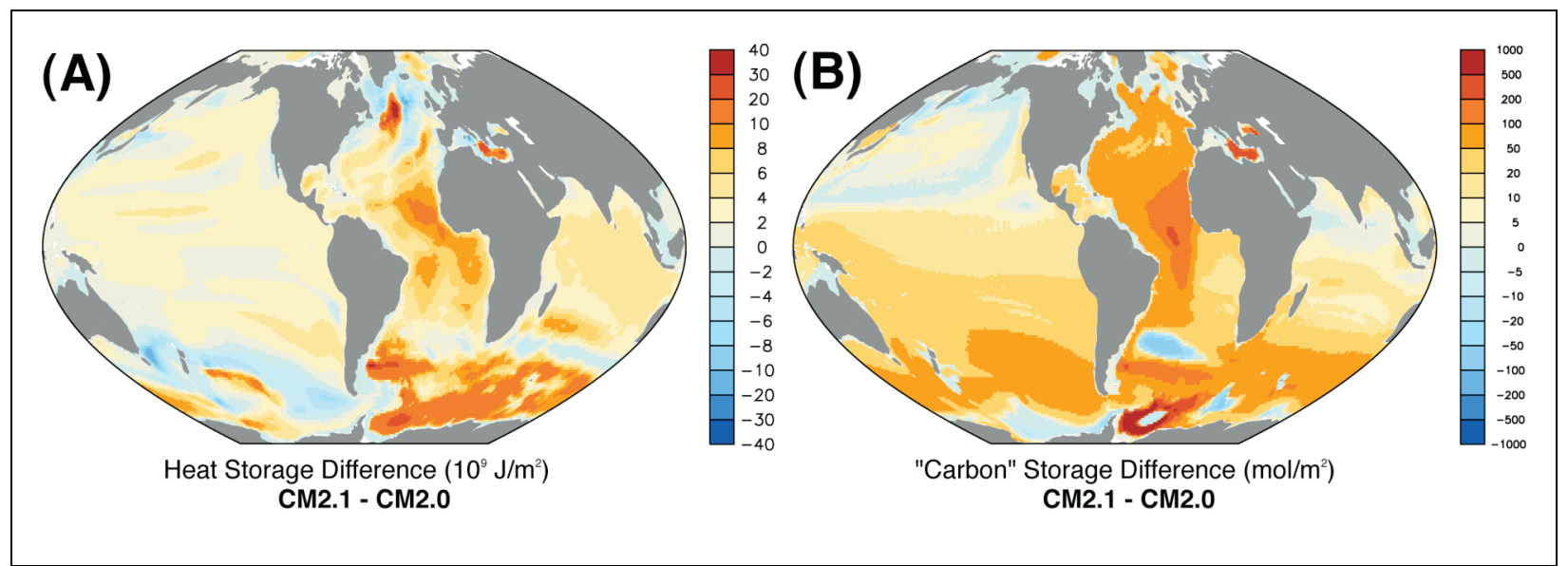

Figure 5: The difference in the (A) vertically integrated heat storage; and (B) the implied "carbon" storage (column inventory) between the CM2.1 and CM2.0 experiments over the period from 2000 to 2300 . We calculated the storage of both heat and carbon over the last 20 years of each run (2281-2300) and subtracted the storage from the first 20 years of each run (2001-2020). We then subtracted the results of CM2.0 from CM2.1. 